\title{
Insecticide resistance in indoor and outdoor-resting Anopheles gambiae in Northern Ghana
}

\author{
Majidah Hamid-Adiamoh 1,2 (10, Alfred Amambua-Ngwa 1,2, Davis Nwakanma², Umberto D'Alessandro², \\ Gordon A. Awandare ${ }^{1}$ and Yaw A. Afrane $1,3^{*}$
}

\begin{abstract}
Background: Selection pressure from continued exposure to insecticides drives development of insecticide resistance and changes in resting behaviour of malaria vectors. There is need to understand how resistance drives changes in resting behaviour within vector species. The association between insecticide resistance and resting behaviour of Anopheles gambiae sensu lato (s.l.) in Northern Ghana was examined.
\end{abstract}

Methods: $F_{1}$ progenies from adult mosquitoes collected indoors and outdoors were exposed to DDT, deltamethrin, malathion and bendiocarb using WHO insecticide susceptibility tests. Insecticide resistance markers including voltage-gated sodium channel (Vgsc)-1014F, Vgsc-1014S, Vgsc-1575Y, glutathione-S-transferase epsilon 2 (GSTe2)-114T and acetylcholinesterase (Ace1)-119S, as well as blood meal sources were investigated using PCR methods. Activities of metabolic enzymes, acetylcholine esterase (AChE), non-specific $\beta$-esterases, glutathione-S-transferase (GST) and monooxygenases were measured from unexposed $F_{1}$ progenies using microplate assays.

Results: Susceptibility of Anopheles coluzzii to deltamethrin $24 \mathrm{~h}$ post-exposure was significantly higher in indoor (mortality $=5 \%$ ) than outdoor (mortality $=2.5 \%)$ populations $(P=0.02)$. Mosquitoes were fully susceptible to malathion (mortality: indoor $=98 \%$, outdoor $=100 \%$ ). Susceptibility to DDT was significantly higher in outdoor (mortality $=9 \%$ ) than indoor (mortality $=0 \%$ ) mosquitoes $(P=0.006)$. Mosquitoes were also found with suspected resistance to bendiocarb but mortality was not statistically different (mortality: indoor $=90 \%$, outdoor $=95 \%$. $P=0.30$ ). Frequencies of all resistance alleles were higher in $F_{1}$ outdoor (0.11-0.85) than indoor (0.04-0.65) mosquito populations, while Vgsc-1014F in $\mathrm{F}_{0}$ An. gambiae sensu stricto (s.s) was significantly associated with outdoor-resting behaviour ( $\left.\mathrm{P}=0.01\right)$. Activities of non-specific $\beta$-esterase enzymes were significantly higher in outdoor than indoor mosquitoes (Mean enzyme activity: Outdoor $=: 1.70 / \mathrm{mg}$ protein; Indoor $=1.35 / \mathrm{mg}$ protein. $\mathrm{P}<0.0001)$. AChE activity was also more elevated in outdoor $(0.62 / \mathrm{mg}$ protein) than indoor $(0.57 / \mathrm{mg}$ protein) mosquitoes but this was not significant $(\mathrm{P}=0.08)$. Human blood index (HBI) was predominantly detected in indoor (18\%) than outdoor mosquito populations (3\%).

Conclusions: The overall results did not establish that there was a significant preference of resistant malaria vectors to solely rest indoors or outdoors, but varied depending on the resistant alleles present. Phenotypic resistance was higher in indoor than outdoor-resting mosquitoes, but genotypic and metabolic resistance levels were higher in

\footnotetext{
*Correspondence: YAfrane@ug.edu.gh

${ }^{1}$ West African Centre for Cell Biology of Infectious Pathogens (WACCBIP)

and Department of Biochemistry, Cell and Molecular, University of Ghana, Legon, Ghana

Full list of author information is available at the end of the article
}

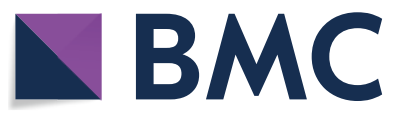

(c) The Author(s) 2020. This article is licensed under a Creative Commons Attribution 4.0 International License, which permits use, sharing, adaptation, distribution and reproduction in any medium or format, as long as you give appropriate credit to the original author(s) and the source, provide a link to the Creative Commons licence, and indicate if changes were made. The images or other third party material in this article are included in the article's Creative Commons licence, unless indicated otherwise in a credit line to the material. If material is not included in the article's Creative Commons licence and your intended use is not permitted by statutory regulation or exceeds the permitted use, you will need to obtain permission directly from the copyright holder. To view a copy of this licence, visit http://creativeco mmons.org/licenses/by/4.0/. The Creative Commons Public Domain Dedication waiver (http://creativecommons.org/publicdomain/ zero/1.0/) applies to the data made available in this article, unless otherwise stated in a credit line to the data. 
outdoor than the indoor populations. Continued monitoring of changes in resting behaviour within An. gambiae s.l. populations is recommended.

Keywords: Anopheles gambiae, Insecticide resistance, Indoor and outdoor behavior, Northern Ghana

\section{Background}

Malaria control and elimination efforts rely heavily on vector control interventions, more specifically on longlasting insecticidal nets (LLINs) and indoor residual spraying (IRS), that involve the use of insecticides [1]. The scale-up of LLIN, has contributed significantly to the decline of malaria burden observed over the last 10-15 years in sub-Saharan Africa [2]. Unfortunately, malaria vectors have developed resistance to the insecticides employed in vector control programmes and indeed to almost all the classes of available insecticides [3]. Insecticide use has been associated with widespread physiological resistance and behavioural changes of malaria vectors which may contribute in maintaining residual malaria transmission $[4,5]$. IRS and LLINs are meant to provoke a knock down or mortal effect on vectors upon contact, targeting their classical anthropophilic (human feeding), late night indoor biting (endophagic) and indoor resting (endophilic) behaviours $[6,7]$. This applies specifically to the most efficient malaria vectors, namely Anopheles arabiensis, Anopheles coluzzii, Anopheles gambiae sensu stricto (s.s.) and Anopheles funestus. Contrary to expectations, in settings where IRS and LLINs were extensively deployed, highly anthropophilic, late-indoor biting and indoor resting vectors have switched to animal feeding and outdoor human feeding following the deployment of vector control activities $[8$, 9]. For instance, An. gambiae sensu lato (s.l.) populations in Bioko Island [10], Ghana [11], Senegal [12] and Tanzania [8] increased outdoor feeding behaviour following extensive intervention with IRS and LLINs. Outdoor biting was also found in naturally endophilic An. funestus populations in Western Kenya [13]. Furthermore, vector populations have adapted to early and early-morning biting, targeting a time when humans are not protected by LLINs [14].

Intriguingly, recent studies done in areas of high IRS and LLINs coverage have shown concurrent indoor and outdoor feeding behaviour within sibling species of $A n$. gambiae s.l. from Benin [15], Ethiopia [16], Libreville [17], Tanzania [8] and Western Kenya [13]. However, there is little evidence of intra-species consistency or differences in insecticide-driven vector resting behaviour. It is plausible that insecticide pressure may select for behavioural changes within species, such that resistant mosquitoes feed and survive indoors while susceptible mosquitoes adopt exophilic behaviour. This can be further modulated by variation in molecular mechanisms that enable survival against insecticides.

Target site and metabolic resistance mechanisms have been shown to confer resistance to insecticides in $A n$. gambiae s.l. [18-20]. Target site resistance involves mutation in the voltage-gated sodium channel (Vgsc) gene, mediating resistance to dichlorodiphenyltrichloroethane (DDT) and pyrethroids [21, 22], as well as acetylcholinesterase (ACE), responsible for carbamate and organophosphate resistance [23, 24]. Increased detoxifying activities of metabolic enzyme families including non-specific esterases, glutathione-S-transferases (GSTs) and monooxygenases (cytochrome P450s) were associated with resistance to the various malaria control insecticides $[25,26]$. Several markers have been identified and widely used for resistance surveillance. In An. gambiae s.l., knockdown resistance (kdr) Vgsc-1014F, Vgsc1014S, Vgsc-1575Y and glutathione-s-transferase epsilon 2 (GSTe2)-114T are markers associated with DDT and pyrethroid resistance [27, 28], whereas Ace1-119S is linked to organophosphates and carbamates resistance [29]. The prevalence of the resistance phenotypes and polymorphisms, as well as enzymatic activities, in association with vector behavioural patterns may help understand the effect of vector interventions and strategies to improve efficacy in specific malaria endemic populations.

Malaria transmission is spatio-temporally heterogenous in Ghana with intensities highly driven along different ecological zones [30, 31]. Recently, malaria prevalence in under 5 years was estimated to be about $40 \%$ [32]. Vector control with IRS and LLINs has been a key strategy for malaria control, where an estimated LLIN usage of $73 \%$ was previously recorded and reduction of malaria burden has been attributed to the effectiveness of these tools [32-34]. Anopheles coluzzii, An. gambiae s.s and $A n$. funestus are the main vector species responsible for transmission [35, 36]. DDT, pyrethroid and carbamate resistance have been reported in these vectors across the country [11,37], but vectors remain susceptible to pirimiphos-methyl, an organophosphate [38].

Northern Ghana is a hyperendemic transmission setting where entomological inoculation rate (EIR) of $>150$ infective bites/person/year has been documented [36]. Currently, IRS and LLINs are extensively being deployed annually in Northern Ghana but the impact of these measures on the behaviour and insecticide resistance in vector populations remains unclear. This study therefore 
investigated the association between resting behaviour of members of An. gambiae s.l. and insecticide resistance and its contribution to residual malaria transmission in Northern Ghana.

\section{Methods}

\section{Study sites}

The study was conducted in two rural communities in Northern Ghana, which are $16 \mathrm{~km}$ apart, Kpalsogu $\left(9.33^{\circ} \mathrm{N}, 1.02^{\circ} \mathrm{W}\right)$ and Libga $\left(9.35^{\circ} \mathrm{N}, 0.51^{\circ} \mathrm{W}\right)$ (Fig. 1). Northern Ghana was chosen because the region continues to experience a high malaria burden, with incidence rate of about $40 \%$ in under-five children [39] and persistent high EIR of $>150$ infective bites/person/year [36, 40], despite scaled-up malaria control interventions. Kpasolgu is one of the sites for annual IRS conducted by the President Malaria Initiative (PMI) and Ghana National Malaria Control Programme (NMCP) since 2008. However, IRS started in Libga in 2008 but was discontinued from 2014. Both communities are in close proximity to dams linked to an irrigation scheme which allows uninterrupted farming activities throughout the year but also supports perennial breeding of mosquitoes [36]. Malaria transmission is seasonal in the areas without irrigation [41].

\section{Mosquito collections and rearing in the insectary}

Indoor and outdoor mosquito collections were conducted in July-November 2017 from each site every other day. Collections were done between 06:00 $\mathrm{h}$ and 09:00 h. Live indoor-resting mosquitoes were sampled using prokopack electrical aspirators [42]. Pit traps [43] were constructed outside houses to attract live outdoorresting mosquitoes which were later collected with prokopack aspirators. Four pit traps were constructed in each village. Each trap was placed about $5 \mathrm{~m}$ from each compound and the houses were $50 \mathrm{~m}$ apart from each other. Both indoor and outdoor collections were done in 6-8 randomly selected compounds in each community. Mosquitoes were transferred into paper cups labeled as per their resting locations.

Mosquitoes were immediately transported to the insectary for morphological identification of species and abdominal status using taxonomic keys [44]. All blood fed, half-gravid and gravid $\mathrm{F}_{0}$ female An. gambiae s.l. were kept in cages to lay eggs. They were provided with laying pads, made of filter paper on top of a wet cotton wool in a Petri dish. Eggs were subsequently allowed to hatch and larvae reared to adult stage.

\section{Insecticide susceptibility bioassay}

Batches of $20-25$ emerging $F_{1}$ adult females (2-5 days old) from 480 wild-caught $\mathrm{F}_{0}$ females, were exposed to insecticide-impregnated papers containing $0.05 \%$ deltamethrin, $5 \%$ malathion, $0.1 \%$ bendiocarb and $4 \%$ DDT following standard World Health Organization (WHO) tube test protocol [45]. Two batches of the same number of mosquitoes were exposed to untreated test papers as negative controls. Mosquitoes were then supplied with $10 \%$ sugar solution in a holding tube and mortality after $24 \mathrm{~h}$ was recorded and scored according to WHO protocol [45]. Dead and surviving mosquitoes were separately stored in $1.5 \mathrm{ml}$ Eppendorf tubes with silica gel for subsequent molecular tests for insecticide resistance mechanisms.

\section{Anopheles species identification}

Genotypic DNA was extracted from the legs of individual $F_{0}$ and $F_{1}$ female mosquitoes using Qiagen QIAxtractor robot. Species Identification to the molecular level was carried out as previously done [46, 47]. All phenotyped $\mathrm{F}_{1}$ and $\mathrm{F}_{0}$ An. gambiae s.l. mosquitoes were analysed for species identification. Primers included in the reaction were those that detect sibling species of $A n$. gambiae complex, including An. arabiensis, An. coluzzii. An. gambiae s.s and Anopheles melas; which are the relevant vectors of malaria in Ghana [48].

\section{Analyses of target site modifications}

From each resting location, 50 mosquitoes were selected per insecticide for genotyping of insecticide resistance polymorphisms in phenotyped mosquitoes. Selection was done using dplyr package in $\mathrm{R}$ (cran.r-project. org). Similarly, all $480 \mathrm{~F}_{0}$ that lay eggs and the remaining wild mosquitoes that were not selected for egg laying were processed for genotypic assessment of insecticide resistance mechanisms. Single nucleotide polymorphism (SNP) markers of insecticide resistance were screened from DNA of each specimen using a TaqMan SNP genotyping probe-based assays [49]. These markers include Vgsc-1014F, Vgsc-1014S and Vgsc-1575Y for target site resistance mutations to DDT and pyrethroids in voltage-gated sodium channel [21, 22, 27]; Ace1-119S mutation, marker of resistance to carbamates and organophosphates [29] and Gste2-114T, a molecular marker of metabolic resistance to DDT [28]. Analysis of allele frequencies of $k d r$ mutations was conducted in the F1 generation of the An. coluzzii alone because they were the majority species encountered in the study sites.

\section{Metabolic enzyme activity assays}

Other subsets of emerging $F_{1}$ adult females (2-5 days old) were immediately frozen in $-20{ }^{\circ} \mathrm{C}$ for biochemi$\mathrm{cal}$ assays. The frozen specimens were analysed for activities of metabolic enzymes including AChE, non-specific $\beta$-esterases, GSTs and monooxygenases (oxidases). $50 \mathrm{~F}_{1}$ 


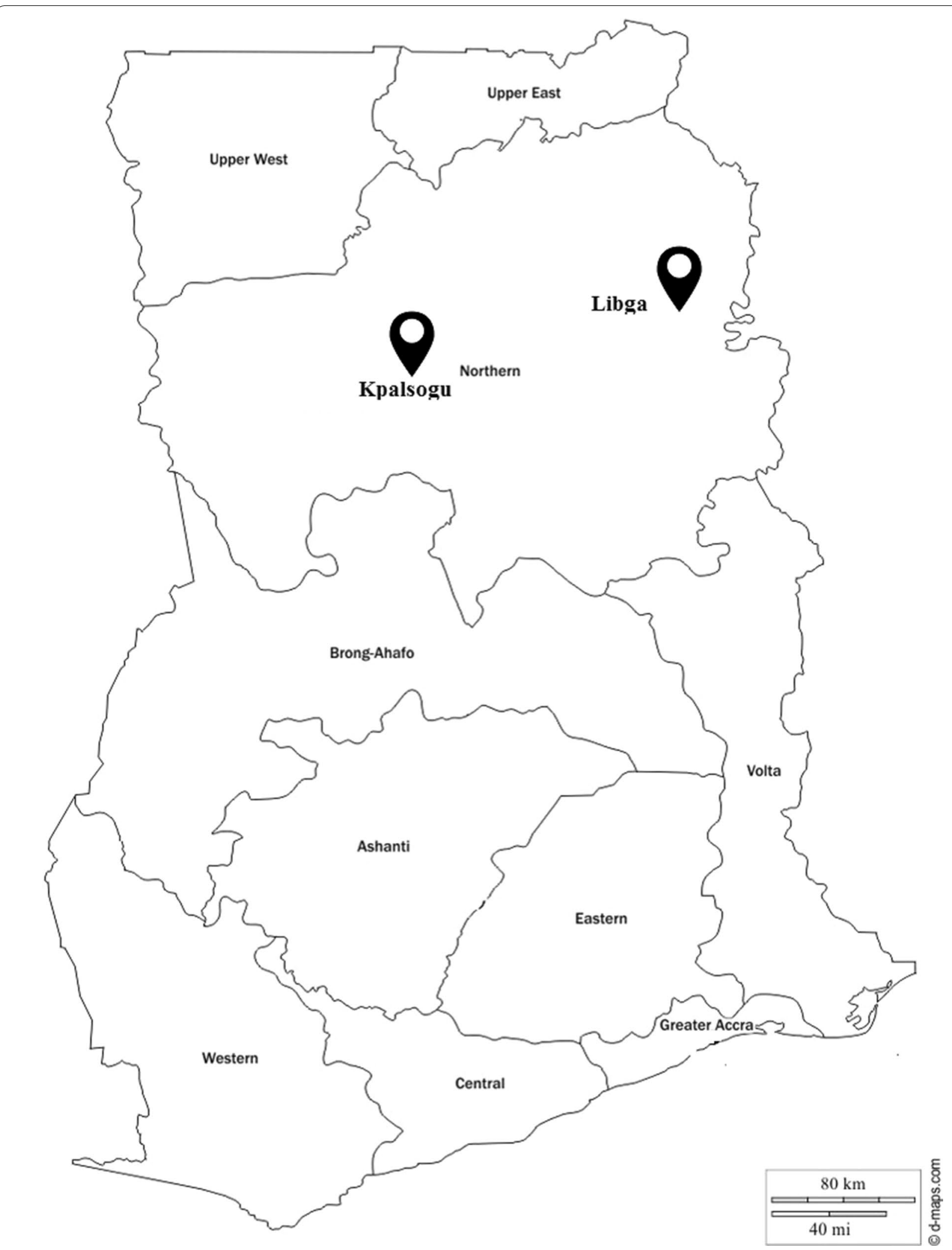

Fig. 1 Map of study sites 
mosquitoes were analysed from each of the study localities and they were not exposed to any insecticide prior to the assays. Microplate assay standard protocols as described [50] were followed for each enzyme, where all assays were run in triplicates and along with Kisumu strain as susceptible control population.

Briefly, individual whole adult mosquitoes (enzyme source) were homogenized in potassium phosphate $\left(\mathrm{KPO}_{4}\right)$ buffer and substrates to respective enzymes were added as well as chromogenic agents. Absorbance was measured using Varioskan Lux multimode microplate reader (Thermo Scientific) at specific wavelengths depending on the enzyme being measured. Acetylcholine esterase was measured at $414 \mathrm{~nm}$ in the presence of acetylthiocholine iodide (ATCH) as substrate; while $\beta$-esterases at $540 \mathrm{~nm}$ in the presence of $\beta$-naphthyl acetate. Monooxygenes (cytochrome P450) level was determined using 3, 3', 5, 5'-Tetramethyl-Benzidine Dihydrochloride (TMBZ) and absorbance captured at $620 \mathrm{~nm}$. Lastly, glutathione- $S$-transferase with 1-chloro-2, 4'-dinitrobenzene $(\mathrm{cDNB})$ at $340 \mathrm{~nm}$. Total protein from individual mosquitoes was also analysed to standardize the mean enzyme activity of the test samples.

\section{Analysis of blood meal sources}

Blood meal origins were determined from DNA extracted from the abdomens of blood-fed $F_{0}$ mosquitoes using the multiplex PCR protocol [51] modified by including primers that could amplify donkey and horse. This assay involves amplification of mitochondrial cytochrome B of An. gambiae vertebrate hosts including cow, dog, donkey, goat, human, horse and pig from a single mosquito specimen.

\section{Data analysis}

Data from both study sites were pooled together as there was no significant difference in the results obtained. The level of insecticide susceptibility of mosquitoes was evaluated following WHO 2016 criteria [45]. Pearson's Chi squared test was used to determine the differences in mortality to insecticides by resistance allele and their frequencies between indoor and outdoor mosquito populations. Odds ratio was applied to determine the association between resistance phenotype and frequency of resistance alleles in $F_{1}$ mosquito populations exposed to insecticides.

Mean activities of each enzyme per mg of protein were compared between mosquitoes from the two resting locations and the reference susceptible strain, using one-way analysis of variance (ANOVA) with HolmSidak's multiple comparisons test. The mean enzyme activities between indoor and outdoor mosquitoes were compared using Mann-Whitney test. Human (HBI) and animal (BBI) blood indices were each calculated as total number of mosquitoes positive for human and animal DNA as a proportion of all blood fed mosquitoes expressed in percentage. All statistical analyses were performed using Stata/IC 15.0 (2017 StataCorp LP) and GraphPad Prism 8.0.1 software. P value of $<0.05$ was considered significant in all data interpretations.

\section{Results \\ Anopheles mosquito species composition}

A total of 3675 mosquitoes were collected during the study. Of these, 1122 (31\%) were female An. gambiae s.l., 2358 (64\%) An. funestus complex and 195 (5\%) Culicine mosquitoes. The majority $(58 \%, 652)$ of $A n$. gambiae s.l. mosquitoes were found resting outdoors than indoors $(42 \%, 470)$. Anopheles coluzzii was the predominant species, both indoors $(36 \%, 375)$ and outdoors $(39 \%, 413)$, followed by An. arabiensis $(3 \%, 33)$ indoors and outdoors (12\%, 125), and An. gambiae s.s. indoors $(2 \%, 27)$ and outdoors $(8 \%, 83)$. Five (5) hybrids of An. coluzzii/gambiae s.s. were also identified.

\section{Phenotypic resistance in $\mathrm{F}_{1}$ Anopheles coluzzii populations} Overall, a total of 780 mosquitoes (indoor: 380, outdoor: 400) were exposed to insecticides (Additional file 1: Table S1) from about 160 (indoor) and 320 (outdoor) $F_{0}$ adults that successfully laid eggs. Species identification of all phenotyped samples revealed $98 \%$ of $\mathrm{F}_{1}$ progeny were $A n$. coluzzii both indoors and outdoors while the remaining species (An. arabiensis and An. gambiae) represented 2\%. Mortality was generally higher in outdoor mosquitoes than the indoor populations. A $24-\mathrm{h}$ post-exposure mortality of $0 \%$ and $9 \%$ (95\% CI 3-12\%) was observed for DDT with progeny of mosquitoes from indoor and outdoor respectively (Fig. 2) and this difference was statistically significant (Pearson $X^{2}=7.58, \mathrm{df}=1, \mathrm{P}=0.006$ ). Progeny of mosquitoes exposed to deltamethrin showed an overall mortality of $5 \%$ (95\% CI 1-12\%) for indoor mosquitoes and $2.5 \%$ (95\% CI 8-34\%) for outdoor-resting mosquitoes (Pearson $X^{2}=5.44, \mathrm{df}=1, \mathrm{P}=0.02$ ).

The indoor and outdoor mosquitoes exposed to bendiocarb showed suspected resistance with mortality of 90\% (95\% CI 64-95\%) in the indoor population and 95\% (95\% CI 87-100\%) in the outdoor population (Pearson $X^{2}=1.07, \mathrm{df}=1, \mathrm{P}=0.30$ ). Both the indoor and outdoor populations were fully susceptible to malathion, with $98 \%$ and $100 \%$ (95\% CI $87-100 \%$ ) mortality for indoor and outdoor mosquitoes, respectively (Pearson $X^{2}=2.02$, $\mathrm{df}=1, \mathrm{P}=0.16)$. There was no observed mortality $(0 \%)$ in the controls for all insecticides tested. 


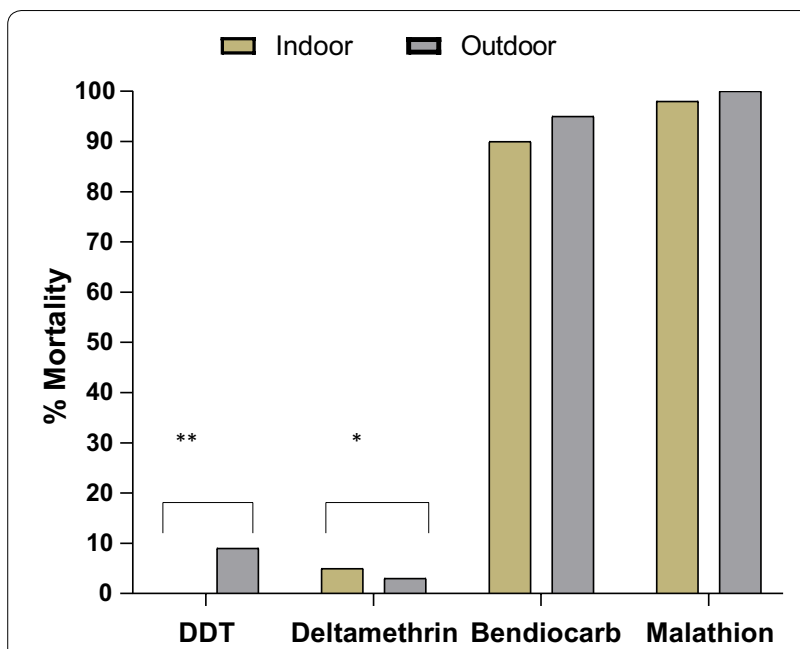

Fig. 2 Phenotypic resistance to the four insecticides tested in indoor and outdoor mosquitoes. ${ }^{*} P=0.02 .{ }^{* *} P=0.006$

Detection of resistance alleles in $F_{1}$ An. coluzzii populations Resistance-associated allele frequencies were higher in outdoor-resting mosquitoes than the indoor population (Table 1). Vgsc-1014F and GSTe2-114T alleles were the most common in both phenotypically resistant and susceptible indoor and outdoor mosquitoes. In the deltamethrin-resistant mosquitoes, Vgsc-1014F frequency was 0.65 (indoor) and 0.67 (outdoor). However in the DDT-resistant mosquitoes, $V g s c-1014 F$ frequency was 0.65 (indoor) and 0.73 (outdoor). These observed differences were not statistically significant between the indoor and outdoor mosquito populations (Deltamethrin: Pearson $X^{2}=0.22, \mathrm{df}=1, \mathrm{P}=0.64$. DDT: Pearson $X^{2}=0.41, \mathrm{df}=1, \mathrm{P}=0.52$ ). The carriage of $\mathrm{Vgsc}-1014 \mathrm{~F}$ mutation was strongly associated with resistance to deltamethrin $(\mathrm{OR}=5.46, \mathrm{P}=0.001,95 \% \mathrm{CI} 1.94-15.41)$ but not with DDT resistance $(\mathrm{OR}=0.69, \mathrm{P}=0.75,95 \% \mathrm{CI}$ $0.066-7.14)$. No Vgsc-1014S allele was detected in any of the mosquitoes.

Vgsc-1575Y mutation was detected mainly in the deltamethrin-resistant outdoor An. coluzzii populations (frequency=0.27). GSTe2-114T mutation was significantly higher in outdoor-resting (0.85) mosquitoes than the indoor (0.56) DDT-resistant mosquitoes (Pearson $X^{2}=5.73, \mathrm{df}=1, \mathrm{P}=0.02$ ). This mutation was also identified in mosquitoes resistant to deltamethrin (indoor $=0.62$, outdoor $=0.84$ ).

Ace1-119S was detected in a single indoor and an outdoor An. coluzzii specimens that survived bendiocarb exposure. It was also found in a single bendiocarb-resistant outdoor mosquito. The allele was detected only in malathion-susceptible mosquitoes at frequency of 0.08 (indoor) and 0.12 (outdoor) with no significant difference (Pearson $X^{2}=0.003, \mathrm{df}=1, \mathrm{P}=0.96$ ).

\section{Detection of resistance alleles in $\mathrm{F}_{0}$ An. gambiae populations}

The frequency of resistance alleles between the indoor and outdoor mosquitoes varied by mosquito species. Whereas Vgsc-1014S was not detected in the $\mathrm{F}_{1} \mathrm{An}$.

Table 1 Frequencies (proportions) of resistance alleles in indoor and outdoor $F_{1}$ An. coluzzii populations based on insecticide resistance phenotypes (dead and alive)

\begin{tabular}{|c|c|c|c|c|c|c|c|c|}
\hline \multirow[t]{2}{*}{ Deltamethrin } & \multicolumn{2}{|c|}{ Vgsc-1014F } & \multicolumn{2}{|c|}{ Vgsc-1575Y } & \multicolumn{2}{|c|}{ GSTe2-114T } & \multicolumn{2}{|c|}{ Ace1-119S } \\
\hline & $\begin{array}{l}\text { Dead } \\
(\mathrm{N}=8)\end{array}$ & $\begin{array}{l}\text { Alive } \\
(\mathrm{N}=81)\end{array}$ & $\begin{array}{l}\text { Dead } \\
(\mathrm{N}=8)\end{array}$ & $\begin{array}{l}\text { Alive } \\
(\mathrm{N}=82)\end{array}$ & $\begin{array}{l}\text { Dead } \\
(\mathrm{N}=8)\end{array}$ & $\begin{array}{l}\text { Alive } \\
(\mathrm{N}=82)\end{array}$ & Dead & Alive \\
\hline Indoor & 0.5 & 0.65 & 0 & 0.07 & 0.5 & 0.62 & & \\
\hline Outdoor & 1 & 0.67 & 1 & 0.27 & 1 & 0.84 & & \\
\hline DDT & $(\mathrm{N}=4)$ & $(\mathrm{N}=49)$ & $(\mathrm{N}=0)$ & $(\mathrm{N}=50)$ & $(\mathrm{N}=4)$ & $(\mathrm{N}=52)$ & & \\
\hline Indoor & 0 & 0.65 & 0 & 0.04 & 0 & 0.56 & & \\
\hline Outdoor & 0.75 & 0.73 & 0 & 0.11 & 1 & 0.85 & & \\
\hline Bendiocarb & & & & & & & $(\mathrm{N}=55)$ & $(\mathrm{N}=3)$ \\
\hline Indoor & & & & & & & 0.06 & 1 \\
\hline Outdoor & & & & & & & 0 & 1 \\
\hline Malathion & & & & & & & $(\mathrm{N}=59)$ & $(\mathrm{N}=1)$ \\
\hline Indoor & & & & & & & 0.08 & 0 \\
\hline Outdoor & & & & & & & 0.12 & 0 \\
\hline
\end{tabular}

$\mathrm{N}$ represents overall number of mosquito population positive by PCR for individual resistance allele in each indoor and outdoor populations 
coluzzii, it was observed mainly in the $\mathrm{F}_{0} A n$. arabiensis resting outdoors. Vgsc-1014F mutation was significantly higher in outdoor (0.99) resting mosquitoes compared to those indoors (0.77) in An. gambiae s.s. (Pearson $X^{2}=31.6, \mathrm{df}=2, \mathrm{P}=0.001$ ) (Table 2). There was an indication of association of outdoor-resting behaviour with resistance in An. gambiae s.s. population carrying the Vgsc-1014F mutation $(\mathrm{OR}=0.05, \mathrm{P}=0.01,95 \%$ CI 0.005 0.419). Although, An. coluzzii was the predominant species collected both indoors and outdoors, the difference in the frequency of this mutation in indoor (0.65) and outdoor $(0.70)$ populations was not statistically significant (Pearson $X^{2}=0.7, \mathrm{df}=2, \mathrm{P}=0.4$ ). However, the higher prevalence of the mutation in indoor (0.48) than the outdoor (0.21) An. arabiensis population was significant (Pearson $\left.X^{2}=6.42, \mathrm{df}=2, \mathrm{P}=0.04\right)$. Vgsc- $1014 S$ was mainly found in indoor An. arabiensis (0.42).

Vgsc-1575Y was detected at an almost similar level (frequencies: Indoor $=0.21$, outdoor $=0.2$ ) in An. coluzii populations. Further, no significant difference was observed in indoor (0.30) and outdoor (0.18) An. gambiae s.s. (Pearson $X^{2}=1.2, \mathrm{df}=1, \mathrm{P}=0.27$ ).

Ace1-119S mutation was most frequent in An. gambiae s.s., although there was no statistically significant difference in the frequencies between indoor $(0.25)$ and outdoor (0.31) populations (Pearson $X^{2}=0.2, \mathrm{df}=1, \mathrm{P}=0$. 65). The prevalence was 0.1 in indoor and outdoor $A n$. coluzzii.

\section{Metabolic enzyme activities in $\mathrm{F}_{1}$ An. coluzzii populations} An overall highly significant elevated levels of $\mathrm{AChE}\left(\mathrm{F}_{2}\right.$, $\left.{ }_{237}=55.93, \quad \mathrm{P}<0.0001\right)$ and $\beta$-esterase $\left(F_{2,237}=159.0\right.$, $\mathrm{P}<0.0001)$ activities were observed in both indoor and outdoor mosquito populations compared to the susceptible reference strain, Kisumu (Figs. 3a-d). Conversely, in both mosquito populations, the activities of the GSTs and monooxygenases were less relative to Kisumu but this was not significant in monooxygenase activity $\left(\mathrm{F}_{2}\right.$, ${ }_{237}=0.6589, \mathrm{P}=0.52$ ).

AChE activity was not significantly higher in the outdoor $(0.62 / \mathrm{mg}$ protein) than the indoor $(0.57 / \mathrm{mg}$ protein) population (Mann-Whitney $\mathrm{U}=5037, \mathrm{Z}=-1.73$, $\mathrm{P}=0.08$ ). The elevation in enzyme activity was found (Table 3) to be 2.48-fold (indoor) and 2.7 fold (outdoor) significantly higher than in Kisumu $(\mathrm{P}<0.0001)$. Similarly, non-specific $\beta$-esterase activity in the outdoorresting mosquitoes (1.70/mg protein) was significantly more than the indoor mosquitoes (1.35) (Mann-Whitney $\mathrm{U}=0.5, \mathrm{Z}=-8.33, \mathrm{P}<0.0001$ ); with 1.69 (indoor) and 2.13 (outdoor) significant fold changes $(\mathrm{P}<0.0001)$. No significant difference was detected in the level of GST activity between the two mosquito populations (indoor: $0.01 / \mathrm{mg}$ protein, outdoor: $0.02 / \mathrm{mg}$ protein, (MannWhitney $\mathrm{U}=5709, \mathrm{Z}=-0.29, \mathrm{P}=0.78)$. Monooxygenase activities also showed a similar level in both indoor and outdoor mosquitoes (mean activity $=0.21 / \mathrm{mg}$ protein, (Mann-Whitney $\mathrm{U}=4989, \mathrm{Z}=-1.84, \mathrm{P}=0.07$ ). The fold difference in monooxygenase activities in Kisumu population (1.11) was not statistically significant $(\mathrm{P}=0.59)$.

\section{Host blood meal sources of wild $F_{0}$ mosquitoes}

A total of 165 out of 214 blood-fed mosquitoes were successfully identified to have fed either on human or animal hosts. The overall vertebrate positivity rate was higher in indoor-resting mosquitoes (Table 4), predominantly in $A n$. coluzzii, which was the most abundant species in the study sites. Overall human blood index (HBI) was $21 \%$ and again more prominent in indoor (18\%) than outdoor (3\%) mosquitoes. $69 \%$ of HBI was detected from indoor An. coluzzii, followed by $17 \%$ in outdoor An. coluzzii. Anopheles arabiensis was found with only 9\% (indoor) and $1 \%$ (outdoor) HBI, while $1 \%$ HBI was identified in indoor An. gambiae only.

The principal animal blood meal source was from goat, representing $36 \%$ of indoor against $8 \%$ of outdoor-resting

Table 2 Frequencies (proportions) of resistance alleles in the wild $\mathrm{F}_{\mathbf{0}}$ indoor and outdoor An. gambiae sl populations

\begin{tabular}{|c|c|c|c|c|c|c|c|c|c|c|}
\hline & \multicolumn{2}{|c|}{ Vgsc-1014F } & \multicolumn{2}{|c|}{ Vgsc-1014S } & \multicolumn{2}{|c|}{ Vgsc-1575Y } & \multicolumn{2}{|c|}{ GSTe2-114T } & \multicolumn{2}{|c|}{ Ace1-119S } \\
\hline & Indoor & Outdoor & Indoor & Outdoor & Indoor & Outdoor & Indoor & Outdoor & Indoor & Outdoor \\
\hline \multirow[t]{2}{*}{ An. arabiensis } & 0.48 & 0.21 & 0.42 & 0.39 & 0 & 0.02 & 0.13 & 0.07 & 0 & 0.01 \\
\hline & $N=21$ & $N=75$ & $N=19$ & $N=97$ & & $N=119$ & $N=15$ & $N=54$ & & $N=26$ \\
\hline \multirow[t]{2}{*}{ An. coluzzii } & 0.65 & 0.7 & 0.01 & 0.01 & 0.21 & 0.2 & 0.84 & 0.86 & 0.01 & 0.01 \\
\hline & $N=352$ & $N=401$ & $N=125$ & $N=122$ & $N=358$ & $N=403$ & $N=213$ & $N=307$ & $N=364$ & $N=401$ \\
\hline \multirow[t]{2}{*}{ An. gambiaes.s } & 0.77 & 0.99 & 0 & 0.5 & 0.3 & 0.18 & 0.25 & 0.13 & 0.25 & 0.31 \\
\hline & $N=22$ & $N=74$ & $N=5$ & $N=2$ & $N=23$ & $N=76$ & $N=12$ & $N=56$ & $N=24$ & $N=80$ \\
\hline \multirow[t]{2}{*}{ An. coluzzii/gambiaes.s } & 1 & 1 & & & & & & & & \\
\hline & $N=3$ & $N=2$ & & & & & & & & \\
\hline
\end{tabular}


a

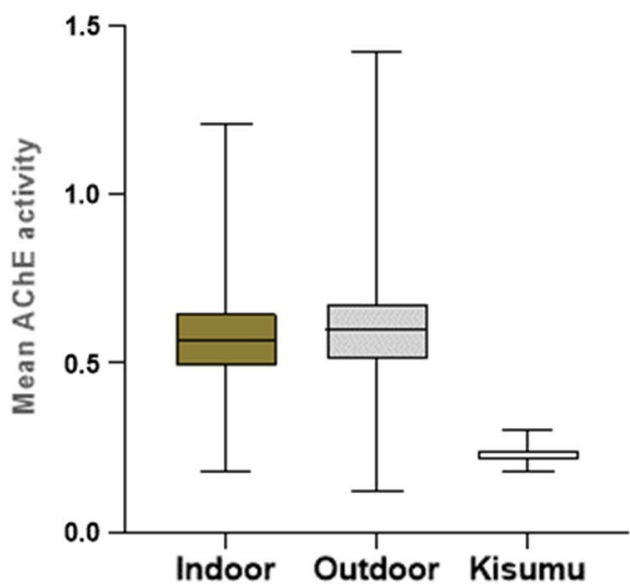

c

Glutathione-S-Transferase (GST)

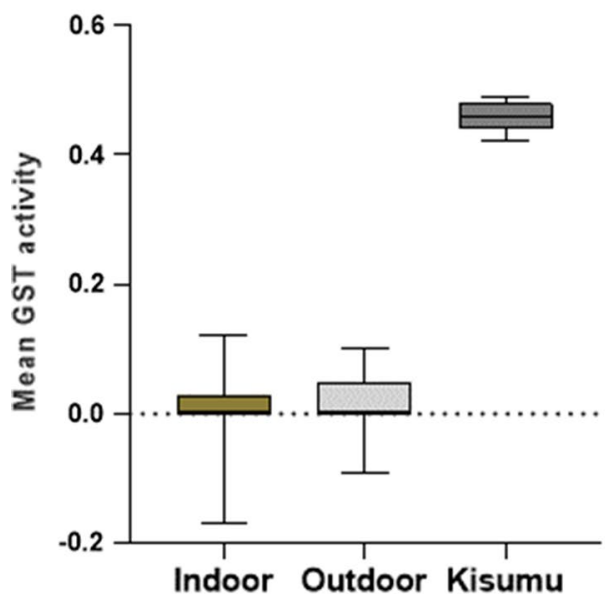

b

Beta Esterases

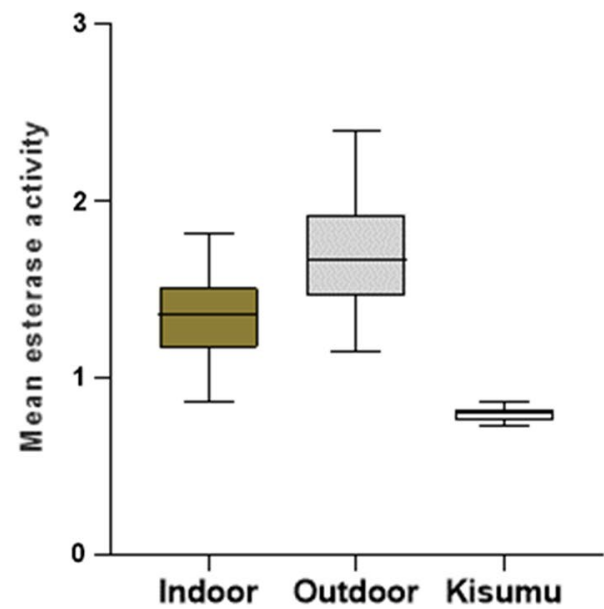

d

Monooxygenases

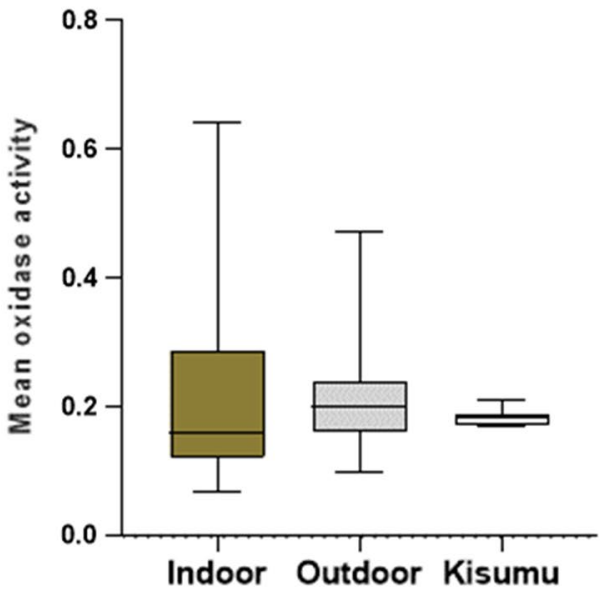

Fig. 3 Mean enzyme activities observed in individual enzymes in indoor and outdoor mosquitoes and the susceptible reference strain, Kisumu

An. coluzzii. The other animal blood sources included cows, dogs, donkeys, horses and pigs and were mainly detected in indoor An. coluzzii specimens. Fewer (4\%) An. arabiensis resting indoors fed on animal blood compared to the outdoor population (10\%), similar to An. gambiae s.s. indoor $(0.6 \%)$ and outdoor (1.2\%) population. Mixed human and goat blood meal was identified from a single indoor An. coluzzii specimen. Also, mixed cow and goat meal were found in three outdoor An. coluzzii specimens and one outdoor An. gambiae s.s. specimen.

\section{Discussion}

In this study, phenotypic resistance was found to be higher in indoor-resting than outdoor-resting $A n$. coluzzii progeny. Higher resistance-associated alleles and elevated activities of two metabolic enzymes were however recorded in the outdoor-resting population. Overall, there was not a significant association between insecticide resistance and resting location of the mosquito populations; but there was a tendency for An. coluzzii to rest indoors when phenotypically resistant to DDT and An. gambiae s.s. to rest outdoors when resistance was genotypically due to $V g s c-1014 F$ mutation. Enhanced $\mathrm{AChE}$ and $\beta$-esterases activities were also prominent in outdoor-resting $\mathrm{F}_{1}$ An. coluzzii. Moreover, human and animal blood meal indices were higher in indoor than the outdoor mosquito population but with no statistical significance.

A probe into insecticide-driven genetic adaptation in vector population at intra-species level was a main 
Table 3 Mean activities of individual enzyme and the fold change in mosquito populations relative to Kisumu

\begin{tabular}{lllll}
\hline Enzyme & $\begin{array}{l}\text { Mosquito } \\
\text { population }\end{array}$ & $\begin{array}{l}\text { Mean enzyme } \\
\text { activity (95\% } \\
\text { Cl) }\end{array}$ & Fold change & P-value \\
\hline AChE & Kisumu & $0.23(0.22-0.24)$ & \\
& Indoor & $0.57(0.54-0.60)$ & 2.48 & $<0.0001$ \\
& Outdoor & $0.62(0.58-0.66)$ & 2.7 & $<0.0001$ \\
B-esterase & Kisumu & $0.80(0.78-0.81)$ & \\
& Indoor & $1.35(1.31-1.39)$ & 1.69 & $<0.0001$ \\
& Outdoor & $1.70(1.65-1.76)$ & 2.13 & $<0.0001$ \\
GST & Kisumu & $0.46(0.45-0.47)$ & \\
& Indoor & $0.01(0.0-0.01)$ & 0.02 & $<0.0001$ \\
& Outdoor & $0.02(0.01-0.02)$ & 0.04 & $<0.0001$ \\
Monooxyge- & Kisumu & $0.19(0.18-0.19)$ & & \\
nase & Indoor & $0.21(0.18-0.23)$ & 1.11 & 0.59 \\
& Outdoor & $0.21(0.19-0.22)$ & 1.11 & 0.59 \\
\hline
\end{tabular}

Table 4 Proportion of blood meal origin of the indoor and outdoor-resting mosquito populations

\begin{tabular}{|c|c|c|c|}
\hline & $\begin{array}{l}\text { An. arabiensis } \\
\text { Proportion (n) }\end{array}$ & $\begin{array}{l}\text { An. coluzzii } \\
\text { Proportion (n) }\end{array}$ & $\begin{array}{l}\text { An. gambiae } \\
\text { Proportion (n) }\end{array}$ \\
\hline \multicolumn{4}{|l|}{ Human } \\
\hline Indoor & $0.02(3)$ & $0.15(24)$ & $0.01(1)$ \\
\hline Outdoor & $0.01(1)$ & $6(0.04)$ & 0 \\
\hline \multicolumn{4}{|l|}{ Cow } \\
\hline Indoor & 0 & $0.01(2)$ & 0 \\
\hline Outdoor & 0 & $0.01(2)$ & 0 \\
\hline \multicolumn{4}{|l|}{ Dog } \\
\hline Indoor & 0 & $0.05(8)$ & 0 \\
\hline Outdoor & 0 & $0.01(2)$ & 0 \\
\hline \multicolumn{4}{|l|}{ Donkey } \\
\hline Indoor & 0 & $0.04(7)$ & 0 \\
\hline Outdoor & 0 & $0.01(1)$ & 0 \\
\hline \multicolumn{4}{|l|}{ Goat } \\
\hline Indoor & $0.04(7)$ & $0.36(59)$ & $0.01(2)$ \\
\hline Outdoor & $0.07(12)$ & $0.08(13)$ & $0.01(1)$ \\
\hline \multicolumn{4}{|l|}{ Horse } \\
\hline Indoor & 0 & $0.02(3)$ & 0 \\
\hline Outdoor & $0.01(2)$ & 0 & 0 \\
\hline \multicolumn{4}{|l|}{ Pig } \\
\hline Indoor & 0 & $0.01(1)$ & 0 \\
\hline Outdoor & $0.01(2)$ & $0.01(1)$ & 0 \\
\hline \multicolumn{4}{|l|}{ Mixed hosts } \\
\hline $\begin{array}{l}\text { Indoor } \\
\text { (human + goat) }\end{array}$ & 0 & $0.01(1)$ & 0 \\
\hline $\begin{array}{l}\text { Outdoor } \\
\text { (cow+goat) }\end{array}$ & 0 & $0.02(3)$ & $0.01(1)$ \\
\hline
\end{tabular}

interest in this study. It was hypothesized that higher resistance levels in indoor compared to the outdoor populations, due to increased contact with insecticide which amplifies their propensity to develop resistance [52]. This was mainly evident in the $\mathrm{F}_{1} A n$. coluzzii populations exposed to insecticides where indoor mosquitoes were less susceptible to three out of four insecticides. Phenotypic resistance was especially high in DDT-exposed indoor populations while genotypic resistance and enzymatic activities were more prevalent in all outdoor $\mathrm{F}_{1}$ mosquito populations. This may be due to selection pressure from prolonged use of DDT for IRS until it was recently switched to pirimiphos-methyl, an organophosphate. Cross-resistance from other pyrethroids used in LLINs may also contribute [53].

This study showed an association between outdoorresting behaviour in $\mathrm{F}_{0}$ An. gambiae s.s. population and $V g s c-1014 F$ mutation. High frequencies of resistance markers associated with DDT resistance, Vgsc-1575Y and GSTe2-114T, were also observed in both $\mathrm{F}_{0}$ and $\mathrm{F} 1$ indoor and outdoor An. coluzzii populations. These may result from selection pressure due to the widespread use of similar insecticides for both public health and agriculture. As noted, year-round agriculture is practiced in the study sites where crops as rice and tomatoes are specifically cultivated with pesticides such as pyrethroids and carbamates predominantly used for pest control $[54,55]$. This could further explain why there were no significant difference in frequencies between the indoor and outdoor populations. Notably, resistance has been previously reported at varying levels to DDT and deltamethrin across all vector species in Ghana $[53,56]$ and the neighboring countries including Benin [19], Burkina Faso [27] and Togo [57]. High frequencies of resistance loci may compromise the effectiveness of vector control in the study areas that could subsequently accentuate residual transmission [41].

Target site polymorphisms may not fully explain resistance in vector populations [58], thus the possible metabolic mechanisms involved were probed. Significant increase in the activities of $\mathrm{AChE}$ and $\beta$-esterases were identified, both of which have been associated with resistance to the insecticides tested [59]. Consistently, the observed fold change in $\beta$-esterases activities which was significantly higher than the susceptible strain, may demonstrate a possible role in deltamethrin resistance in the vector populations as previously reported [60, 61]. On the other hand, the decreased levels of GSTs and monooxygenases detected may indicate that they do not contribute to the DDT and deltamethrin resistance in the study mosquito populations. Therefore, genotypic mechanism alone may be mediating the documented DDT resistance in these mosquito populations. Interestingly, 
an increased activity of AChE was identified despite low level of Ace1-119S and no phenotypic resistance in the carbamate and organophosphate insecticides in the study. This may likely reflect other role of this enzyme, which may not be related to resistance in the vector population. Since there was no documented use of carbamate insecticide for IRS in this region except for agricultural use [30], perhaps this resistance selection may be from agriculture use.

Human and animal blood indices were found to be higher in indoor-resting mosquitoes than the outdoor population despite a higher outdoor collection. This indicates that in spite of the fact that the study areas were under high IRS and LLINs interventions, mosquitoes were able to have either fed on their host indoors or outdoors and still successfully rested indoors despite interventions; thus retained their indoor-resting behaviour. Plausibly, the blood-fed endophilic population could be among the indoor-resistant populations that are capable of maintaining contact with insecticides due to their age and feeding status [62,63]. This scenario could also expose human to infective bites and possible malaria risk thus promoting residual malaria transmission under high intervention as earlier described [4]. Due to logistical reasons, circum-sporozoite detection could not be undertaken.

The predominant vector species identified was $A n$. coluzzii, which is known to be highly endophilic and anthropophilic [64], however, the results here suggested that this vector population were displaying high zoophilic behaviour. The abundant presence of animals in the study areas and reduced access to human host due to intervention may have driven zoophagy and exophagy in this vector species as previously suggested $[65,66]$. Further studies could explore the dynamics of this behaviour and its implication on the control efforts in the study region.

\section{Conclusions}

This study demonstrated that An. coluzzii phenotypically resistant to DDT had a higher propensity for indoorresting behaviour, while outdoor-resting tendency was found in those phenotypically-resistant to deltamethrin. Also, An. coluzzii with increased AChE and $\beta$-esterases activity, and An. gambiae s.s with Vgsc-1014F mutation displayed outdoor-resting behaviour. Mosquitoes resting indoors were found to have fed more on both human and animals than their outdoor counterparts. These findings highlight variation in response of mosquitoes within the same species to insecticide-based interventions. Continued monitoring of vector behaviours in surveillance programmes is recommended, to help in the control of malaria.

\section{Supplementary information}

Supplementary information accompanies this paper at https://doi. org/10.1186/s12936-020-03388-1.

Additional file 1: Table S1. Number of indoor and outdoor test mosquitoes exposed and susceptibility rate to individual insecticides. Data on the number of mosquito populations exposed to insecticides and the susceptibility rate.

\section{Abbreviations}

Ace-1: Acetylcholinesterase 1; DDT: Dichlorodiphenyltrichloroethane; DNA: Deoxyribonucleic acid; GSTe2: Glutathione-s-transferase epsilon 2; HBI: Human blood index; IRS: Indoor residual spraying; Kdr: Knockdown resistance; LLIN: Long-lasting insecticidal net; NMCP: National Malaria Control Programme; PCR: Polymerase chain reaction; PMI: President Malaria Initiative; SNP: Single nucleotide polymorphism; Vgsc: Voltage-gated sodium channel; WHO: World Health Organization.

\section{Acknowledgements}

We thank Messrs Isaac Sraku, Abdul Rahim Mohammed, Dhikrullahi Shittu, Osei Kwaku Akuoko, Sylvester Coleman and Malick Jammeh for their assistance in the field work for this study.

\section{Authors' contributions}

MHA designed, performed the laboratory work, analyzed data and drafted the manuscript. YAA conceived and supervised the study, analyzed data and revised the manuscript. AAN and DA supervised study and revised the manuscript. UDA and GAA revised the manuscript. All authors read and approved the final manuscript.

\section{Funding}

This work was supported by funds from a Wellcome Trust DELTAS Africa grant (DEL-15-007: Awandare), the National Institute of Health (R01 A1123074) and University of Ghana Research Funds (URF/9/ILG-078/2015-2016). Majidah Hamid-Adiamoh was supported by a WACCBIP-Wellcome Trust DELTAS PhD fellowship. The DELTAS Africa Initiative is an independent funding scheme of the African Academy of Sciences (AAS)'s Alliance for Accelerating Excellence in Science in Africa (AESA) and supported by the New Partnership for Africa's Development Planning and Coordinating Agency (NEPAD Agency) with funding from the Wellcome Trust (107755/Z/15/Z: Awandare) and the UK government. The views expressed in this publication are those of the author(s) and not necessarily those of AAS, NEPAD Agency, Wellcome Trust or the UK government.

\section{Data availability statement}

All relevant data are within the paper. No supporting Information is available.

\section{Ethical approval and consent to participate}

Ethical approval was obtained from the Institutional Review Board of the Noguchi Memorial Institute for Medical Research (NMIMR), University of Ghana. Verbal informed consent of the village leaders and compound/household heads were also taken before mosquitoes were collected from the study villages.

\section{Consent for publication}

Not applicable.

\section{Competing interests}

The authors declare that they have no competing interests.

\section{Author details}

${ }^{1}$ West African Centre for Cell Biology of Infectious Pathogens (WACCBIP) and Department of Biochemistry, Cell and Molecular, University of Ghana, Legon, Ghana. ${ }^{2}$ Medical Research Council Unit, The Gambia at the London School of Hygiene \& Tropical Medicine, Banjul, Gambia. ${ }^{3}$ Department of Medical Microbiology, College of Health Sciences, University of Ghana, Legon, Accra, Ghana. 
Received: 10 March 2020 Accepted: 25 August 2020

Published online: 31 August 2020

\section{References}

1. WHO. Global malaria programme. Global technical strategy for malaria, 2016-2030. Geneva: World Health Organization; 2015.

2. WHO. World malaria report 2019. Geneva: World Health Organization; 2019.

3. Hemingway J, Ranson $\mathrm{H}$. Insecticide resistance in insect vectors of human diseases. Annu Rev Entomol. 2000;45:371-91.

4. Killeen GF. Characterizing, controlling and eliminating residual malaria transmission. Malar J. 2014;13:330.

5. Sokhna C, Ndiath $\mathrm{MO}$, Rogier $\mathrm{C}$. The changes in mosquito vector behaviour and the emerging resistance to insecticides will challenge the decline of malaria. Clin Microbiol Infect. 2013;19:902-7.

6. Huho B, Briët O, Seyoum A, Sikaala C, Bayoh N, Gimnig J, et al. Consistently high estimates for the proportion of human exposure to malaria vector populations occurring indoors in rural Africa. Int J Epidemiol. 2013;42:235-47.

7. Pluess B, Tanser FC, Lengeler C, Sharp BL. Indoor residual spraying for preventing malaria. Cochrane Database Syst Rev. 2010;4:CD006657.

8. Russell TL, Govella NJ, Azizi S, Drakeley CJ, Kachur SP, Killeen GF. Increased proportions of outdoor feeding among residual malaria vector populations following increased use of insecticide-treated nets in rural Tanzania. Malar J. 2011;10:80

9. Thomsen EK, Koimbu G, Pulford J, Jamea-Maiasa S, Ura Y, Keven $J B$, et al. Mosquito behavior change after distribution of bednets results in decreased protection against malaria exposure. J Infect Dis. 2017:215:790-7.

10. Meyers Jl, Pathikonda S, Popkin-Hall ZR, Medeiros MC, Fuseini G, Matias A, et al. Increasing outdoor host-seeking in Anopheles gambiae over 6 years of vector control on Bioko Island. Malar J. 2016;15:239.

11. Tchouassi DP, Quakyi IA, Addison EA, Bosompem KM, Wilson MD, Appawu MA, et al. Characterization of malaria transmission by vector populations for improved interventions during the dry season in the Kpone-on-Sea area of coastal Ghana. Parasit Vectors. 2012;5:212.

12. Trape JF, Tall A, Diagne N, Ndiath O, Ly AB, Faye J, et al. Malaria morbidity and pyrethroid resistance after the introduction of insecticide-treated bednets and artemisinin-based combination therapies: a longitudinal study. Lancet Infect Dis. 2011;11:925-32.

13. Degefa T, Yewhalaw D, Zhou G, Lee MC, Atieli H, Githeko AK, et al. Indoor and outdoor malaria vector surveillance in western Kenya: implications for better understanding of residual transmission. Malar J. 2017;16:443.

14. Ototo EN, Mbugi JP, Wanjala CL, Zhou G, Githeko AK, Yan G. Surveillance of malaria vector population density and biting behaviour in western Kenya. Malar J. 2015;14:244.

15. Akogbéto MC, Salako AS, Dagnon F, Aïkpon R, Kouletio M, Sovi A, et al. Blood feeding behaviour comparison and contribution of Anopheles coluzzii and Anopheles gambiae, two sibling species living in sympatry, to malaria transmission in Alibori and Donga region, northern Benin, West Africa. Malar J. 2018:17:307.

16. Kibret S, Wilson GG. Increased outdoor biting tendency of Anopheles arabiensis and its challenge for malaria control in Central Ethiopia. Public Health. 2016;141:143-5.

17. Mourou J-R, Coffinet T, Jarjaval F, Cotteaux C, Pradines E, Godefroy L, et al. Malaria transmission in Libreville: results of a one year survey. Malar J. 2012;11:40.

18. Clarkson CS, Miles A, Harding NJ, Weetman D, Kwiatkowski D, Donnelly $M$, et al. The genetic architecture of target-site resistance to pyrethroid insecticides in the African malaria vectors Anopheles gambiae and Anopheles coluzzii. bioRxiv. 2018.

19. Djègbè I, Agossa FR, Jones CM, Poupardin R, Cornelie $S$, Akogbéto $M$, et al. Molecular characterization of DDT resistance in Anopheles gambiae from Benin. Parasit Vectors. 2014;7:409.

20. Ranson H, N'Guessan R, Lines J, Moiroux N, Nkuni Z, Corbel V. Pyrethroid resistance in African anopheline mosquitoes: what are the implications for malaria control? Trends Parasitol. 2011;27:91-8.

21. Martinez-Torres D, Chandre F, Williamson MS, Darriet F, Bergé JB, Devonshire $\mathrm{AL}$, et al. Molecular characterization of pyrethroid knockdown resistance $(\mathrm{kdr})$ in the major malaria vector Anopheles gambiae s.s. Insect Mol Biol. 1998;7:179-84.

22. Ranson $H$, Jensen B, Vulule JM, Wang X, Hemingway J, Collins FH. Identification of a point mutation in the voltage-gated sodium channel gene of Kenyan Anopheles gambiae associated with resistance to DDT and pyrethroids. Insect Mol Biol. 2000;9:491-7.

23. Essandoh J, Yawson AE, Weetman D. Acetylcholinesterase (Ace-1) target site mutation 119S is strongly diagnostic of carbamate and organophosphate resistance in Anopheles gambiae s.s. and Anopheles coluzzii across southern Ghana. Malar J. 2013;12:404.

24. Djogbenou LS, Pasteur N, Bio-Bangana S, Baldet T, Irish SR, Weill M, et al. Malaria vectors in the Republic of Benin: distribution, of species and molecular forms of the Anopheles gambiae complex. Acta Trop. 2010;114:116-22

25. Simma EA, Dermauw W, Balabanidou V, Snoeck S, Bryon A, Clark RM, et al. Genome-wide gene expression profiling reveals that cuticle alterations and P450 detoxification are associated with deltamethrin and DDT resistance in Anopheles arabiensis populations from Ethiopia. Pest Manag Sci. 2019;75:1808-18

26. Hemingway J, Hawkes NJ, McCarroll L, Ranson H. The molecular basis of insecticide resistance in mosquitoes. Insect Biochem Mol Biol. 2004;34:653-65.

27. Jones CM, Liyanapathirana M, Agossa FR, Weetman D, Ranson H, Donnelly $\mathrm{MJ}$, et al. Footprints of positive selection associated with a mutation (N1575Y) in the voltage-gated sodium channel of Anopheles gambiae. Proc Natl Acad Sci USA. 2012;109:6614-9.

28. Mitchell SN, Rigden DJ, Dowd AJ, Lu F, Wilding CS, Weetman D, et al. Metabolic and target-site mechanisms combine to confer strong DDT resistance in Anopheles gambiae. PLoS ONE. 2014;9:e92662.

29. Bass C, Nikou D, Vontas J, Williamson MS, Field LM. Development of high-throughput real-time PCR assays for the identification of insensitive acetylcholinesterase (ace-1R) in Anopheles gambiae. Pestic Biochem Physiol. 2010;96:80-5.

30. Owusu-Agyei S, Kasasa S, Gosoniu L, Adjuik M, Anto F, Asoala V, et al. Spatio-temporal malaria transmission patterns in Navrongo demographic surveillance site, northern Ghana. Malar J. 2013;12:63.

31. Awine T, Malm K, Peprah NY, Silal SP. Spatio-temporal heterogeneity of malaria morbidity in Ghana: analysis of routine health facility data. PLoS ONE. 2018;13:e0191707.

32. Gogue C, Wagman J, Tynuv K, Saibu A, Yihdego Y, Malm K, et al. An observational analysis of the impact of indoor residual spraying in Northern, Upper East, and Upper West Regions of Ghana: 2014 through 2017. Malar J. 2020;19:242.

33. Aregawi M, Malm KL, Wahjib M, Kofi O, Allotey NK, Yaw PN, et al. Effect of anti-malarial interventions on trends of malaria cases, hospital admissions and deaths, 2005-2015, Ghana. Malar J. 2017;16:177.

34. Afoakwah C, Deng X, Onur I. Malaria infection among children underfive: the use of large-scale interventions in Ghana. BMC Public Health. 2018;18:536.

35. Yawson AE, McCall PJ, Wilson MD, Donnelly MJ. Species abundance and insecticide resistance of Anopheles gambiae in selected areas of Ghana and Burkina Faso. Med Vet Entomol. 2004;18:372-7.

36. Coleman S, Dadzie SK, Seyoum A, Yihdego Y, Mumba P, Dengela D, et al. A reduction in malaria transmission intensity in Northern Ghana after 7 years of indoor residual spraying. Malar J. 2017;16:324.

37. Baffour-Awuah S, Annan AA, Maiga-Ascofare O, Dieudonné SD, Adjei-Kusi P, Owusu-Dabo E, et al. Insecticide resistance in malaria vectors in Kumasi, Ghana. Parasit Vectors. 2016:9:633.

38. Dengela D, Seyoum A, Lucas B, Johns B, George K, Belemvire A, et al. Multi-country assessment of residual bio-efficacy of insecticides used for indoor residual spraying in malaria control on different surface types: results from program monitoring in 17 PMI/USAID-supported IRS countries. Parasit Vectors. 2018;11:71.

39. Ahorlu C, Abuaku B, Amratia P, Oppong S, Valle D, Koram K, et al. Detecting local risk factors for residual malaria in northern Ghana using Bayesian model averaging. Malar J. 2018;17:343.

40. Abuaku B, Ahorlu C, Psychas P, Ricks P, Oppong S, Mensah S, et al. Impact of indoor residual spraying on malaria parasitaemia in the BunkpuruguYunyoo District in northern Ghana. Parasit Vectors. 2018;11:555. 
41. Baird JK, Agyei SO, Utz GC, Koram K, Barcus MJ, Jones TR, et al. Seasonal malaria attack rates in infants and young children in northern Ghana. Am J Trop Med Hyg. 2002;66:280-6.

42. Vazquez-Prokopec GM, Galvin WA, Kelly R, Kitron U. A new, cost-effective, battery-powered aspirator for adult mosquito collections. J Med Entomol. 2009;46:1256-9.

43. Muirhead-Thomson RC. A pit shelter for sampling outdoor mosquito populations. Bull World Health Organ. 1958;19:1116-8.

44. Gillies MT, Coetzee M. A Supplement to the Anophelinae of the South of the Sahara (Afrotropical Region). South African Inst Med Res. 1987:55:1-143.

45. WHO. Test procedures for insecticide resistance monitoring in malaria vector mosquitoes. 2nd ed. Geneva: World Health Organization; 2016.

46. Scott JA, Brogdon WG, Collins FH. Identification of single specimens of the Anopheles gambiae complex by the polymerase chain reaction. Am J Trop Med Hyg. 1993:49:520-9.

47. Favia G, Lanfrancotti A, Spanos L, Sidén-Kiamos I, Louis C. Molecular characterization of ribosomal DNA polymorphisms discriminating among chromosomal forms of Anopheles gambiae s.s.. Insect Mol Biol. 2001:10:19-23.

48. Hunt RH, Fuseini G, Knowles S, Stiles-Ocran J, Verster R, Kaiser ML, et al. Insecticide resistance in malaria vector mosquitoes at four localities in Ghana, West Africa. Parasit Vectors. 2011;4:107.

49. Bass C, Nikou D, Donnelly MJ, Williamson MS, Ranson H, Ball A, et al. Detection of knockdown resistance (kdr) mutations in Anopheles gambiae: a comparison of two new high-throughput assays with existing methods. Malar J. 2007;6:111.

50. Brogdon WG, Beach RF, Stewart JM, Castanaza L. Microplate assay analysis of the distribution of organophosphate and carbamate resistance in Guatemalan Anopheles albimanus. Bull World Health Organ. 1988;66:339-46.

51. Kent RJ, Norris DE. Identification of mammalian blood meals in mosquitoes by a multiplexed polymerase chain reaction targeting cytochrome $\mathrm{B}$. Am J Trop Med Hyg. 2005;73:336-42.

52. Kabula B, Kisinza W, Tungu P, Ndege C, Batengana B, Kollo D, et al. Cooccurrence and distribution of East (L1014S) and West (L1014F) African knock-down resistance in Anopheles gambiae sensu lato population of Tanzania. Trop Med Int Health. 2014;19:331-41.

53. Mitchell SN, Stevenson BJ, Muller P, Wilding CS, Egyir-Yawson A, Field $S G$, et al. Identification and validation of a gene causing cross-resistance between insecticide classes in Anopheles gambiae from Ghana. Proc Natl Acad Sci USA. 2012;109:6147-52.

54. Reid MC, McKenzie FE. The contribution of agricultural insecticide use to increasing insecticide resistance in African malaria vectors. Malar J. 2016;15:107.

55. NPASP (Northern Presbyterian Agricultural Service and Partners). Ghana's pesticide crisis: a need for further government action. 2012.
56. Dadzie SK, Chabi J, Asafu-Adjaye A, Owusu-Akrofi O, Baffoe-Wilmot A, Malm K, et al. Evaluation of piperonyl butoxide in enhancing the efficacy of pyrethroid insecticides against resistant Anopheles gambiae s.l. in Ghana. Malar J. 2017;16:342.

57. Djègbè I, Akoton R, Tchigossou G, Ahadji-Dabla KM, Atoyebi SM, Adéoti R, et al. First report of the presence of L1014S Knockdown-resistance mutation in Anopheles gambiae s.s. and Anopheles coluzzii from Togo. West Africa. Wellcome Open Res. 2018;3:30.

58. Donnelly MJ, Corbel V, Weetman D, Wilding CS, Williamson MS, Black WC IV. Does kdr genotype predict insecticide-resistance phenotype in mosquitoes? Trends Parasitol. 2009;25:213-9.

59. Liu N. Insecticide resistance in mosquitoes: impact, mechanisms, and research directions. Annu Rev Entomol. 2015;60:537-59.

60. Ochomo E, Bayoh MN, Brogdon WG, Gimnig JE, Ouma C, Vulule JM, et al. Pyrethroid resistance in Anopheles gambiae ss and Anopheles arabiensis in western Kenya: Phenotypic, metabolic and target site characterizations of three populations. Med Vet Entomol. 2013;27:156-64.

61. Matowo J, Kulkarni MA, Mosha FW, Oxborough RM, Kitau JA, Tenu F, et al. Biochemical basis of permethrin resistance in Anopheles arabiensis from Lower Moshi, north-eastern Tanzania. Malar J. 2010;9:193.

62. Machani MG, Ochomo E, Sang D, Bonizzoni M, Zhou G, Githeko AK, et al. Influence of blood meal and age of mosquitoes on susceptibility to pyrethroids in Anopheles gambiae from Western Kenya. Malar J. 2019;18:112.

63. Collins E, Vaselli NM, Sylla M, Beavogui AH, Orsborne J, Lawrence G, et al. The relationship between insecticide resistance, mosquito age and malaria prevalence in Anopheles gambiae s.I. from Guinea. Sci Rep. 2019;9:8846.

64. Garrett-Jones C, Boreham PFL, Pant CP. Feeding habits of anophelines (Diptera: culicidae) in 1971-78, with reference to the human blood index: a review. Bull Entomol Res. 1980;70:165-85.

65. Stevenson JC, Simubali L, Mbambara S, Musonda M, Mweetwa S, Mudenda T, et al. Detection of Plasmodium falciparum infection in Anopheles squamosus (Diptera: culicidae) in an area targeted for malaria elimination, Southern Zambia. J Med Entomol. 2016;53:1482-7.

66. Mayagaya VS, Nkwengulila G, Lyimo IN, Kihonda J, Mtambala H, Ngonyani $\mathrm{H}$, et al. The impact of livestock on the abundance, resting behaviour and sporozoite rate of malaria vectors in southern Tanzania. Malar J. 2015;14:17.

\section{Publisher's Note}

Springer Nature remains neutral with regard to jurisdictional claims in published maps and institutional affiliations.
Ready to submit your research? Choose BMC and benefit from:

- fast, convenient online submission

- thorough peer review by experienced researchers in your field

- rapid publication on acceptance

- support for research data, including large and complex data types

- gold Open Access which fosters wider collaboration and increased citations

- maximum visibility for your research: over $100 \mathrm{M}$ website views per year

At BMC, research is always in progress.

Learn more biomedcentral.com/submissions 